\title{
Determination of Lisinopril by Flow Injection Analysis Technique
}

\author{
${ }^{1}$ Dakhil Nassir Taha, ${ }^{2}$ Sadiq Jaafer Baqir and ${ }^{1}$ Ahmed Shaalan Khlaif \\ ${ }^{1}$ Department of Chemistry, College of Science, University of Babylon, \\ 51002 Babylon, Iraq \\ ${ }^{2}$ Al-Mustaqbal University College, 51002 Babylon, Iraq \\ ahmedshaalan792@gmail.com,009647814687389
}

\begin{abstract}
The aim of this research is to design a new flow injection analysis unit for the determination of lisinopril through its reaction with NQS at ${ }_{\max } 550 \mathrm{~nm}$. The method involves manufacturing of new valve from a cheap material which can be used in the chemical reactions. The optimum conditions such as sample volume, reagent volume, reagent concentration, flow rate and reaction coil length were studied. Beer's law is obeyed over the concentration range (5-60 ppm) with linearity coefficient $\left(\mathrm{R}^{2}\right)$ of 0.9968 . The relative standard deviation was $1.094 \%$ for $20 \mathrm{ppm}$ lisinopril solution $(\mathrm{n}=3$ ). The method was successfully applied for the determination of lisinopril in pharmaceutical formulations and aqueous solution.
\end{abstract}

$\underline{\text { Key words: Stop flow technique, lisinopril, merging zone, NQS, sample volume, reagent volume }}$

\section{INTRODUCTION}

FIA is defined as "information gathering from a concentration gradient formed from an injected, well defined zone of a fluid, dispersed into a continuous unsegmented stream of a carrier (Meyers et al., 1970). This technique is used to determine different samples such as trace acids (Taha, 2002), iron (II) (Farhood et al., 2017 a, b), aniline blue and malachite green dye (Majeed etal., 2017). Lisinopril (LNP, Fig. 1) (S)-1-(N2-(1carboxy-3-phenylpropyl)-L-lysyl)-L-proline dihydrate is an angiotensin converting enzyme inhibitor used in the treatment of hyper tension and heart failure. Lisinopril is white crystalline powder, many melt in water (American Society of Health-system, US Pharmacopeia Staff, 2008).

It determined through various spectrophotometric methods based on reaction between lisinopril and different reagents (Jamakhandi et al., $2011 \mathrm{a}$, b; Cakar and Popovic, 2012; Ali and Elbashi, 2013; Raghubabu and Sandhyarani, 2015; Shraitah and Okdeh, 2016; Zaheer et al., 2016). Other techniques such as potentiometric methods (Razak et al., 2003) and chromatographic methods (Wagh et al., 2012; Sultana et al., 2013). The proposed method is based on the reaction of lisinopril with NQS in the presence of amonium hydroxide to form reaction which shows an absorption maximum at $550 \mathrm{~nm}$ Fig. 2.

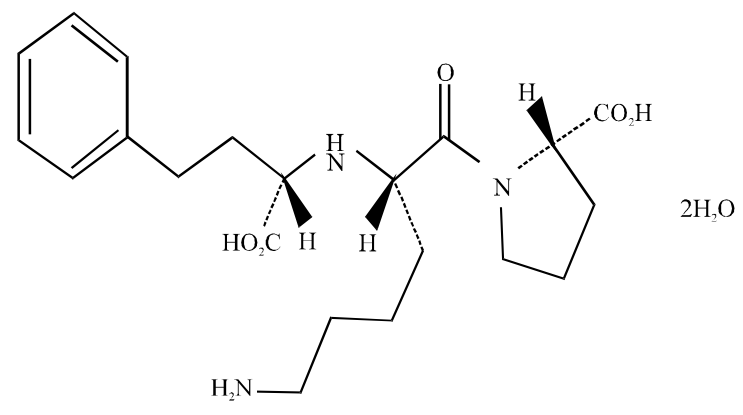

Fig. 1: Structure of lisinopril

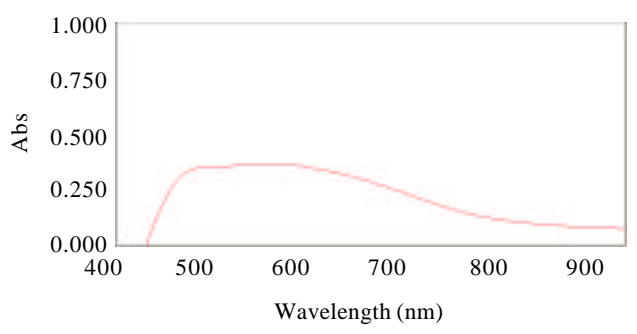

Fig. 2: The spectra of the mixture; Scan spectrum curve

\section{MATERIALS AND METHODS}

Apparatus: All spectral and absorbance measurements were achieved on a UV-visible single beam Labomed.ing (Japan) and double beam (T80). In FIA, a flow cell with $450 \mu \mathrm{L}$ internal volume and $1 \mathrm{~cm}$ path length was utilized

Corresponding Author: Ahmed Shaalan Khlaif, Department of Chemistry, College of Science, University of Babylon, 51002 Babylon, Iraq, ahmedshaalan792@gmail.com, 009647814687389 


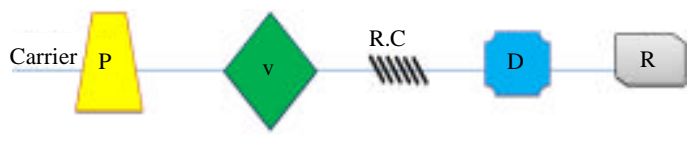

Fig. 3: Manifold employed for FIA-spectrophotometric determination of lisinopril where, V. Injection valve; RC. Reaction Coil; P. Peristaltic pump; R. Recorder and D. Detector

for the absorbance measurements. A one-channel man fold Fig. 2 was employed for the FIA spectrophotometric determination of lisinopril. A peristaltic pump (Ismatec Germany) was used to transport the carries solutions. injection valve was to provide appropriate injection volumes of solutions. Flexible teflon tubing of $(1 \mathrm{~mm})$ internal diameter was used for the peristaltic pump. Reaction Coil (RC) was of teflon and glass with internal diameter of $(1 \mathrm{~mm})$. Balance was utilized to weight the material and $x$-t chart graph recorder (Siemens Germany) was used for recording the peaks.

\section{Preparation of standard solution}

Materials: Freshly stock solutions (50 ppm) of lisinopril were prepared by weight $(0.0025 \mathrm{~g})$ from lisinopril and diluting with a distilled water to the mark in a weighing $(50 \mathrm{~mL})$ volumetric flask. Working solutions were prepared by diluting the above solution by distilled water.

Freshly $(0.01 \mathrm{w} / \mathrm{v} \%)$ of (NQS) was prepared by dissolving $(0.005 \mathrm{~g})$ in $(50 \mathrm{~mL})$ distilled water with continuous stir and concussion. The other solutions were prepared by diluting of the above stock solution. The $20 \% \mathrm{v} / \mathrm{v}$ of $\left(\mathrm{NH}_{4} \mathrm{OH}\right)$ was prepared by diluting $(20 \mathrm{~mL})$ from ammonium hydroxide with distilled water in a $(100 \mathrm{~mL})$ volumetric flask. The other solutions were prepared by dilution of the above stock solution.

\section{Pharmaceutical preparations}

Tablets: Ten tablets of lisinopril were weighed and finally powdered. A weighed amount of the powder equivalent to $0.02 \mathrm{~g}$ of the pure lisinopril was dissolved in hot distilled water and made up to $100 \mathrm{~mL}$ in volumetric flask. The resulting solution was filtered off and was treated as described under recommended procedure.

Procedure for the FIA method: Samples containing different concentrations of lisinopril were prepared by simple dilution with distilled water of the freshly stock solution $(100 \mu \mathrm{g} / \mathrm{mL})$. The FIA spectrophotometric measurements were carried out using the manifold shown in Fig. 3 employing $196.25 \mu \mathrm{L}$ of lisinopril, $(235.5 \mu \mathrm{L})$ of NQS and $(157 \mu \mathrm{L})$ of base with a flow rate of $(12.3 \mathrm{~mL} / \mathrm{min})$ and reaction coil $100 \mathrm{~cm}$. This reaction occurs at ${ }_{\text {max }}$.

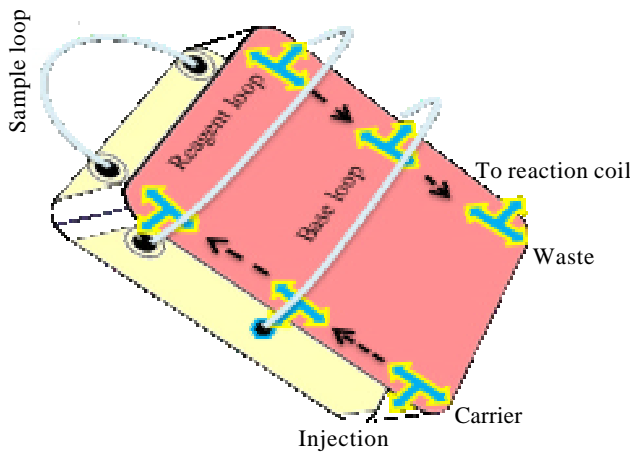

Fig. 4: The valve

Table 1: Effect of order of addition

\begin{tabular}{lc}
\hline Order of addition & Response $(\mathrm{cm})$ \\
\hline (NQS+Lis)+B & 1.1 \\
(NQS+B)+Lis & 0.9 \\
(Lis+NQS)+B & 1.0 \\
\hline
\end{tabular}

$(\mathrm{Lis}+\mathrm{NQS})+\mathrm{B}$

Table 2: Effect of mixing time of reaction

\begin{tabular}{llllllr}
\hline Mixing time & \multicolumn{7}{l}{$------P e a k$ height $(\mathrm{cm})-----$} & Means & SD & RSD (\%) \\
\hline 0 & 1.100 & 1.250 & 1.000 & 1.116 & 0.125 & 11.200 \\
1 & 1.650 & 1.650 & 1.500 & 1.600 & 0.086 & 5.375 \\
3 & 2.000 & 2.000 & 2.000 & 2.000 & 0.000 & 0.000 \\
4 & 2.500 & 2.450 & 2.500 & 2.483 & 0.026 & 1.047 \\
5 & 2.300 & 2.200 & 2.200 & 2.233 & 0.056 & 2.507 \\
\hline
\end{tabular}

\section{RESULTS AND DISCUSSION}

Unit design: A new valve was manufactured from low-cost materials and it can be used in chemical reactions. Figure 4 shows the valve.

Order of addition: The effect of order of addition was studies for the system which is completing and selecting the best response at: flow rate $(8.1 \mathrm{~mL} / \mathrm{min})$, reaction coil $(50 \mathrm{~cm})$, sample volume $(157 \mu \mathrm{L})$, reagent volume $(157 \mu \mathrm{L})$, base volume $(157 \mu \mathrm{L})$, mixing time $(0)$, sample concentration $(50 \mathrm{ppm})$ reagent concentration (NQS) $(0.01 \mathrm{w} / \mathrm{v} \%)$, base concentration $(10 \mathrm{v} / \mathrm{v} \%)$. The results Table 1 and Fig. 5 show that the response which increase at the order of addition $((\mathrm{NQS}+\mathrm{Lis})+\mathrm{B})$ but decrease at the other addition.

Mixing time of reaction: To know the suitable mixing time of reaction this adverb was studied at, flow rate $(8.1 \mathrm{~mL} / \mathrm{min})$, reaction coil $(50 \mathrm{~cm})$, sample volume $(157 \mu \mathrm{L})$, reagent volume $(157 \mu \mathrm{L})$, base volume $(157 \mu \mathrm{L})$, order of addition $((\mathrm{NQS}+\mathrm{Lis})+\mathrm{B})$, sample concentration $(50 \mathrm{ppm})$, reagent concentration $(0.01 \mathrm{w} / \mathrm{v} \%)$, base concentration $(10 \mathrm{v} / \mathrm{v} \%)$. Via. stop time ofreaction the best response can be determined for Table 2 and Fig. 6 reaction between lisinopril and NQS. About 4 min gives the best shows that the time response. 


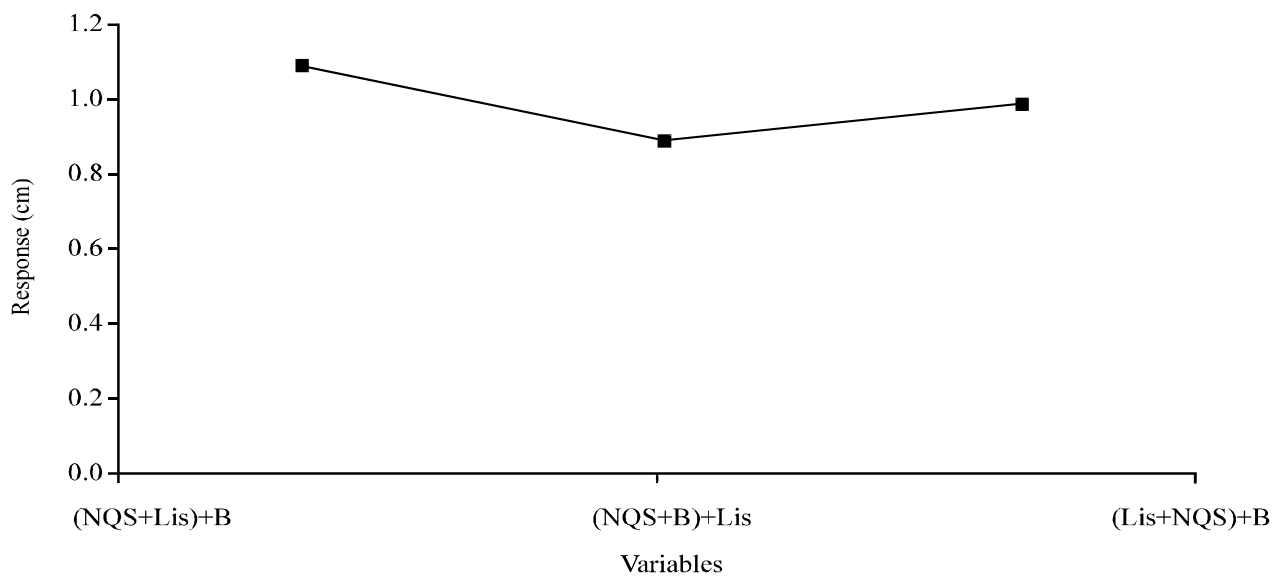

Fig. 5: Effect of order of addition

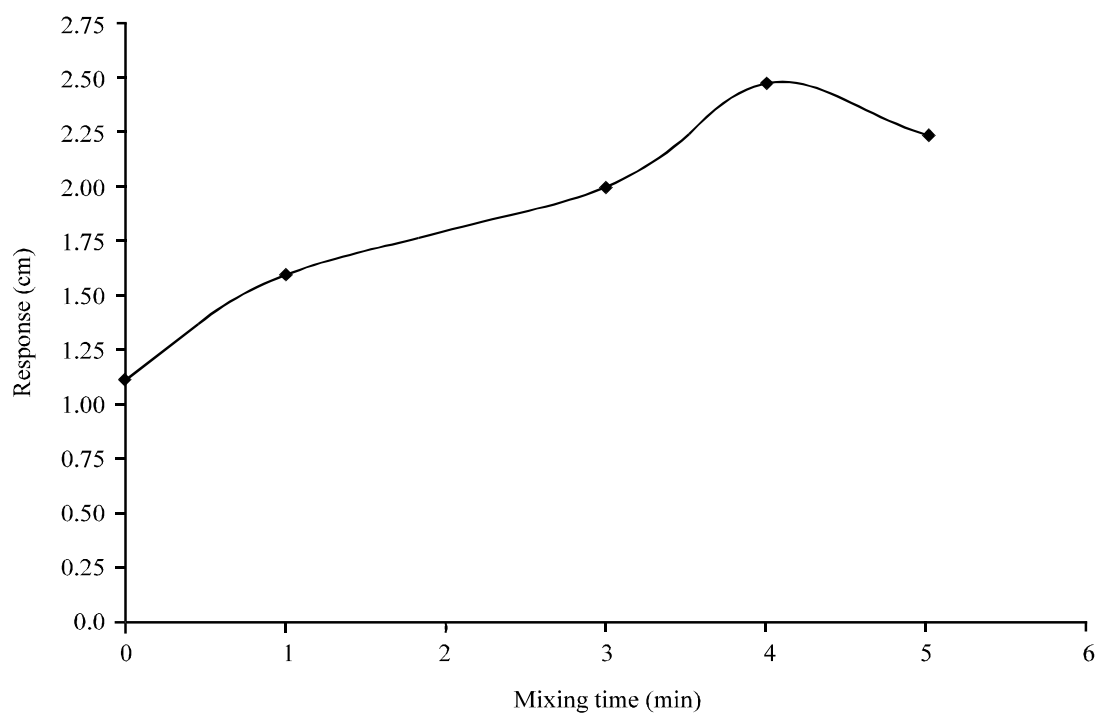

Fig. 6: Effect of reaction mixing time

Table 3: Effect of flow rate

\begin{tabular}{llllllc}
\hline $\begin{array}{l}\text { Flow rate } \\
\text { (mL/min) }\end{array}$ & \multicolumn{7}{c}{------Peak length (cm)------- } & Means & SD & RSD (\%) \\
\hline 3.300 & 0.950 & 1.100 & 1.050 & 1.033 & 0.075 & 7.260 \\
4.900 & 1.350 & 1.350 & 1.350 & 1.350 & 0.000 & 0.000 \\
6.600 & 1.950 & 2.000 & 1.950 & 1.966 & 0.027 & 1.373 \\
8.100 & 2.500 & 2.500 & 2.500 & 2.500 & 0.000 & 0.000 \\
10.000 & 3.200 & 3.000 & 3.000 & 3.066 & 0.114 & 3.718 \\
12.300 & 3.450 & 3.650 & 3.650 & 3.583 & 0.086 & 2.400 \\
13.700 & 2.450 & 2.650 & 2.500 & 2.533 & 0.103 & 4.066 \\
\hline
\end{tabular}

Flow rate: The effect of flow rate was investigated in the range (3.3-3.17 $\mathrm{mL} / \mathrm{min})$ at: mixing time $(4 \mathrm{~min})$, reaction coil $(50 \mathrm{~cm})$, sample volume $(157 \mu \mathrm{L})$, reagent volume $(157 \mu \mathrm{L})$, base volume $(157 \mu \mathrm{L})$, order of addition ((NQS+Lis)+B) sample concentration $(50 \mathrm{ppm})$, reagent concentration $(0.01 \mathrm{w} / \mathrm{v} \%)$, base concentration $(10 \mathrm{v} / \mathrm{v} \%)$. The results in Table 3 and Fig. 7 show that the flow rate of $(12.3 \mathrm{~mL} / \mathrm{min})$ gives the best response.
Table 4: Effect of reagent volume

\begin{tabular}{lcccccc}
\hline $\begin{array}{l}\text { Reagent } \\
\text { volume }(\mu \mathrm{L})\end{array}$ & $--------P e a k$ length-------- & & & \\
$(\mathrm{cm})$ & & Means & SD & RSD (\%) \\
\hline 157.000 & 3.700 & 3.650 & 3.700 & 3.683 & 0.026 & 0.705 \\
196.250 & 2.800 & 2.700 & 3.000 & 2.833 & 0.152 & 5.365 \\
235.500 & 4.050 & 4.250 & 4.050 & 4.116 & 0.115 & 2.793 \\
314.000 & 2.500 & 2.700 & 2.600 & 2.600 & 0.100 & 3.846 \\
\hline
\end{tabular}

Reagent volume: The influence of the reagent volume on the peak height was investigated by using various length of reagent loop with different volume. The results obtained showed that an injection reagent volume of $(235.5 \mu \mathrm{L})$ gave the best response for as shown in Fig. 8 and Table 4. This adverb was studied at: mixing time (4 min), reaction coil $(50 \mathrm{~cm})$, sample volume $(157 \mu \mathrm{L})$, flow rate $(8.1 \mathrm{~mL} / \mathrm{min})$ base volume $(157 \mu \mathrm{L})$, order of addition ((NQS+Lis)+B), sample concentration (50 ppm) reagent concentration $(0.01 \mathrm{w} / \mathrm{v} \%)$, base concentration $(10 \mathrm{v} / \mathrm{v} \%)$. 


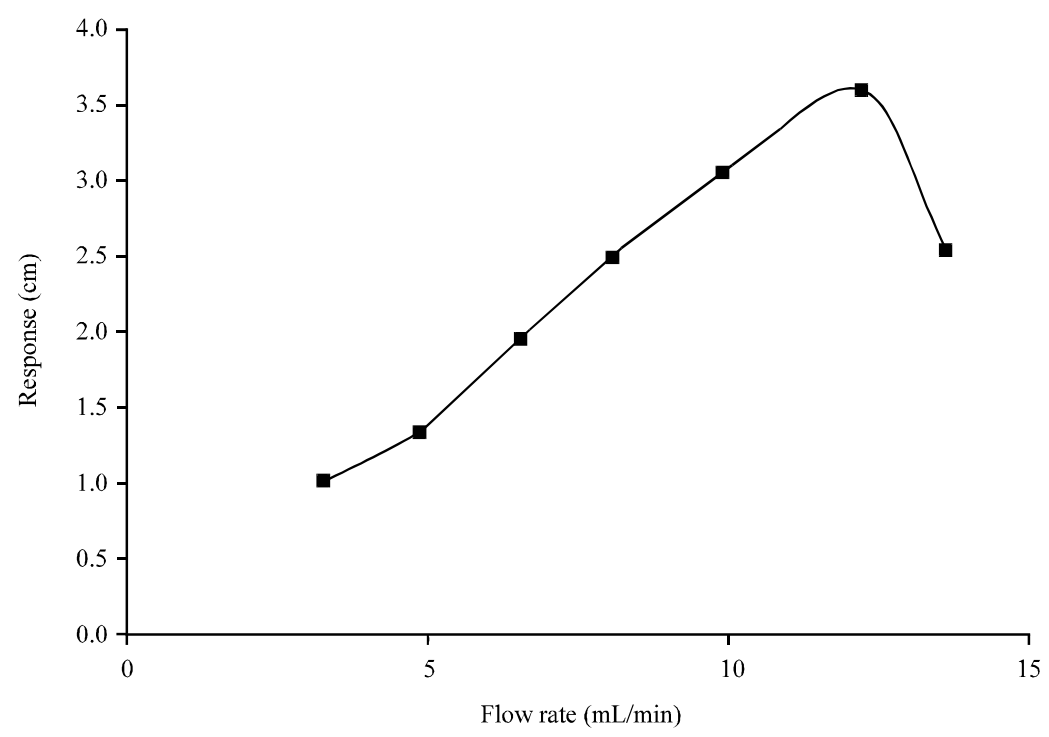

Fig. 7: Effect of flow rate

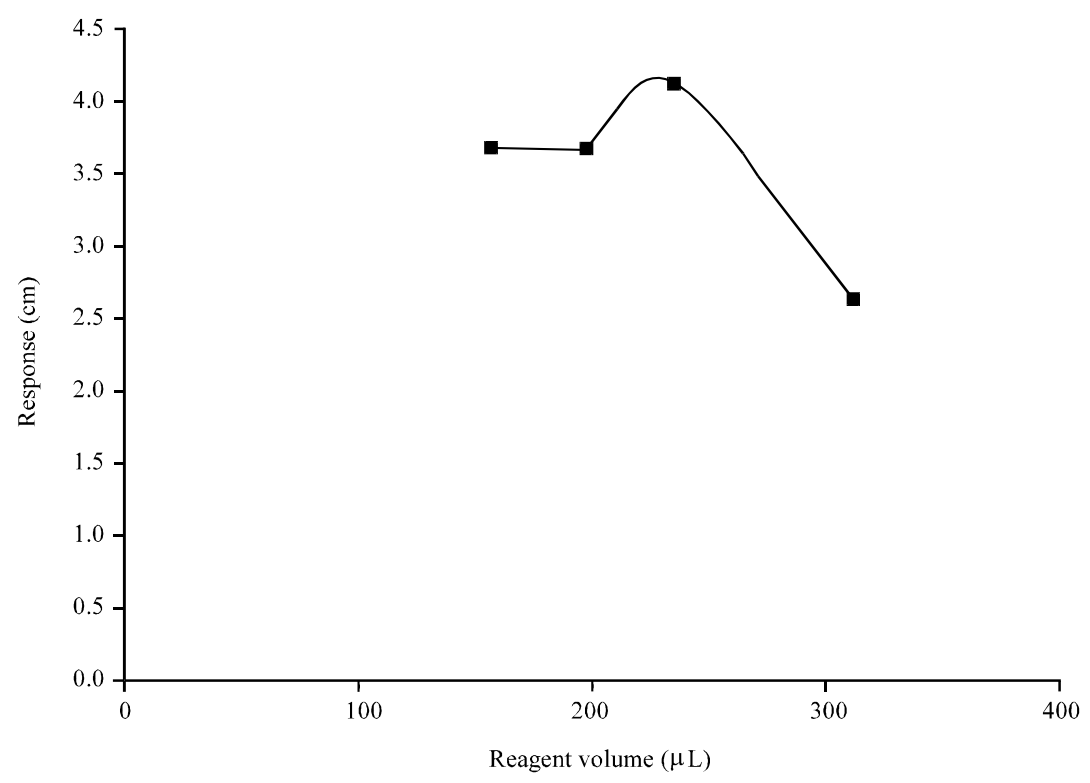

Fig. 8: Effect of reagent volume

Table 5: Effect of sample volume

\begin{tabular}{lcccccr}
\multicolumn{2}{l}{ Table 5: Effect of sample volume } \\
$\begin{array}{l}\text { Sample } \\
\text { volume }(\mu \mathrm{L})\end{array}$ & $\begin{array}{c}c \\
\text { (cm) }\end{array}$ & Means & SD & $\begin{array}{r}\text { RSD } \\
(\%)\end{array}$ \\
\hline 157.000 & 4.100 & 4.000 & 4.100 & 4.066 & 0.057 & 1.401 \\
196.250 & 4.750 & 4.650 & 4.500 & 4.633 & 0.125 & 2.698 \\
235.500 & 3.800 & 3.750 & 3.800 & 3.783 & 0.026 & 0.687 \\
314.000 & 2.100 & 2.100 & 2.100 & 2.100 & 0.000 & 0.000 \\
\hline
\end{tabular}

Effect of sample volume: The effect of sample volume was investigated by injection of different volume through using different sample loop length of. The results obtained showed that an injection sample of $(196.25 \mu \mathrm{L})$ gave the best response for lisinopril as shown in Fig. 9 and Table 5 the above adverb was deliberated at: mixing time $(4 \mathrm{~min})$, reaction coil $(50 \mathrm{~cm})$, reagent volume $(235.5 \mu \mathrm{L})$ flow rate $(8.1 \mathrm{~mL} / \mathrm{min})$, base volume $(157 \mu \mathrm{L})$, order of addition ( $(\mathrm{NQS}+\mathrm{Lis})+\mathrm{B})$, sample concentration $(50$ ppm) reagent concentration $(0.01 \mathrm{w} / \mathrm{v} \%)$, base concentration $(10 \mathrm{v} / \mathrm{v} \%)$.

Effect of base volume: Optimum volume of the base that gives the best response for the reaction between lisinopril and NQS is $(157 \mu \mathrm{L})$ as shown in Table 6 and Fig. 10. The effect of base volume was investigated in the range 


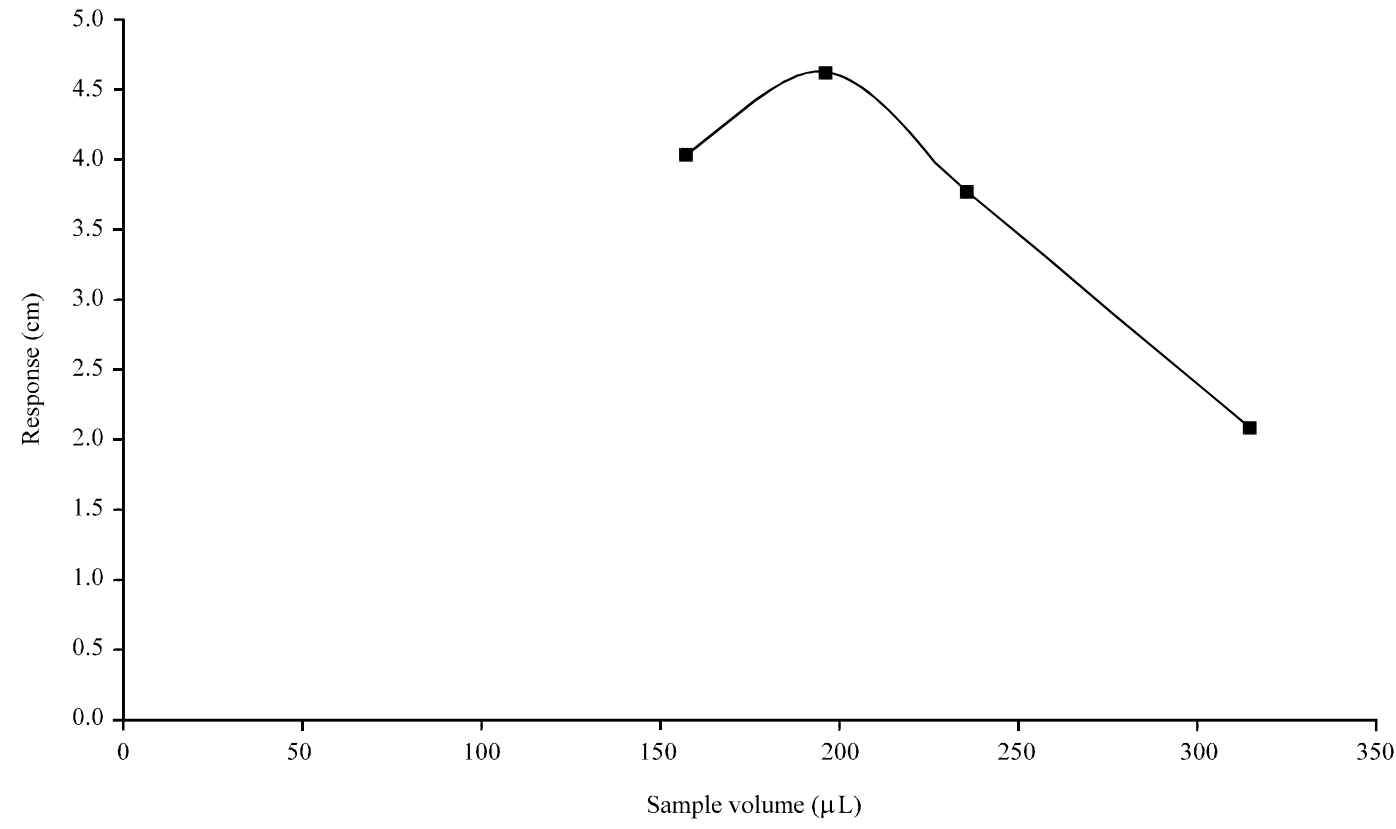

Fig. 9: Effect of sample volume

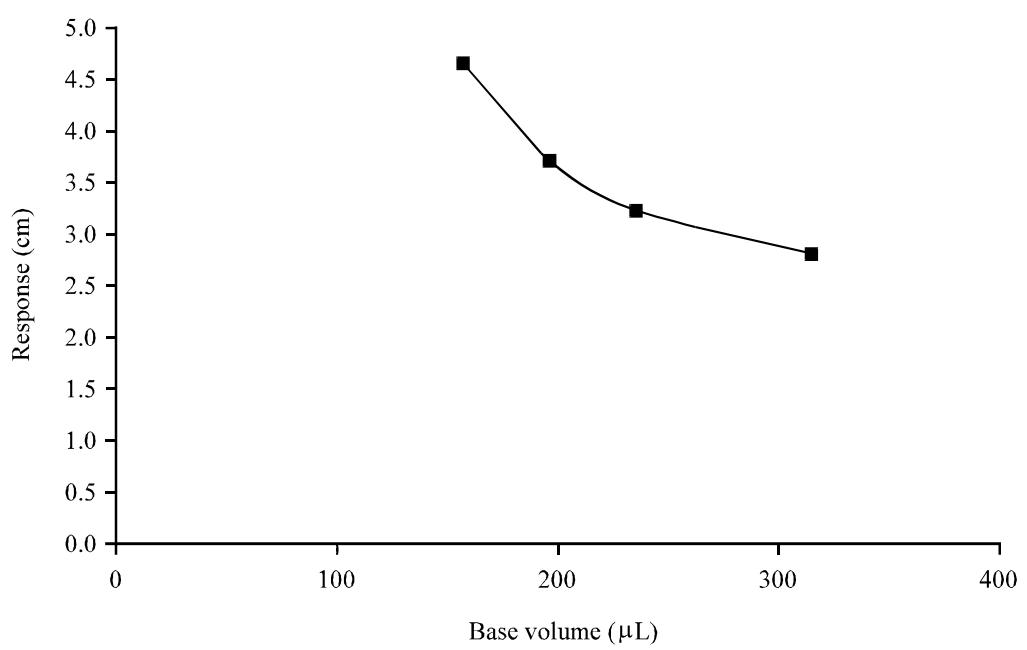

Fig. 10: Effect of base volume

Table 6: Effect of base volume

Base

\begin{tabular}{llllccc} 
volume $(\mu \mathrm{L})$ & \multicolumn{7}{c}{---- Peak length $(\mathrm{cm})----$} & Means & SD & RSD (\%) \\
\hline 157.000 & 4.650 & 4.650 & 4.650 & 4.650 & 0.000 & 0.000 \\
196.250 & 3.800 & 3.600 & 3.700 & 3.700 & 0.100 & 2.702 \\
235.500 & 3.250 & 3.150 & 3.250 & 3.216 & 0.057 & 1.772 \\
314.000 & 2.800 & 2.800 & 2.800 & 2.800 & 0.000 & 0.000 \\
\hline
\end{tabular}

$(157-314 \mu \mathrm{L})$ at: mixing time $(4 \mathrm{~min})$, reaction coil $(50 \mathrm{~cm})$, reagent volume $(235.5 \mu \mathrm{L})$, flow rate $(8.1 \mathrm{~mL} / \mathrm{min})$ sample volume $(196.25 \mu \mathrm{L})$, order of addition ((NQS+Lis)+B), sample concentration (50 ppm) reagent concentration $(0.01 \mathrm{w} / \mathrm{v} \%)$, base concentration $(10 \mathrm{v} / \mathrm{v} \%)$.
Table 7: Effect of reaction coil

\begin{tabular}{llllllc}
$\begin{array}{l}\text { Reaction coil } \\
\text { length (cm) }\end{array}$ & ----Peak length (cm)---- & Means & SD & RSD (\%) \\
\hline 30.000 & 4.250 & 4.300 & 4.200 & 4.250 & 0.050 & 1.176 \\
50.000 & 4.600 & 4.600 & 4.600 & 4.600 & 0.000 & 0.000 \\
100.000 & 4.850 & 4.850 & 4.850 & 4.850 & 0.000 & 0.000 \\
115.000 & 3.400 & 3.250 & 3.300 & 3.316 & 0.075 & 2.261 \\
\hline
\end{tabular}

Effect of reaction coil: The coil length was investigated in the range of $(30-115 \mathrm{~cm})$. The results obtained showed that a coil length of $(100 \mathrm{~cm})$ gave a suitable response for as shown in Fig. 11 and Table 7. This parameter was studied at: mixing time $(4 \mathrm{~min})$, base volume $(157 \mu \mathrm{L})$, reagent volume $(235.5 \mu \mathrm{L})$, flow rate $(8.1 \mathrm{~mL} / \mathrm{min})$ 


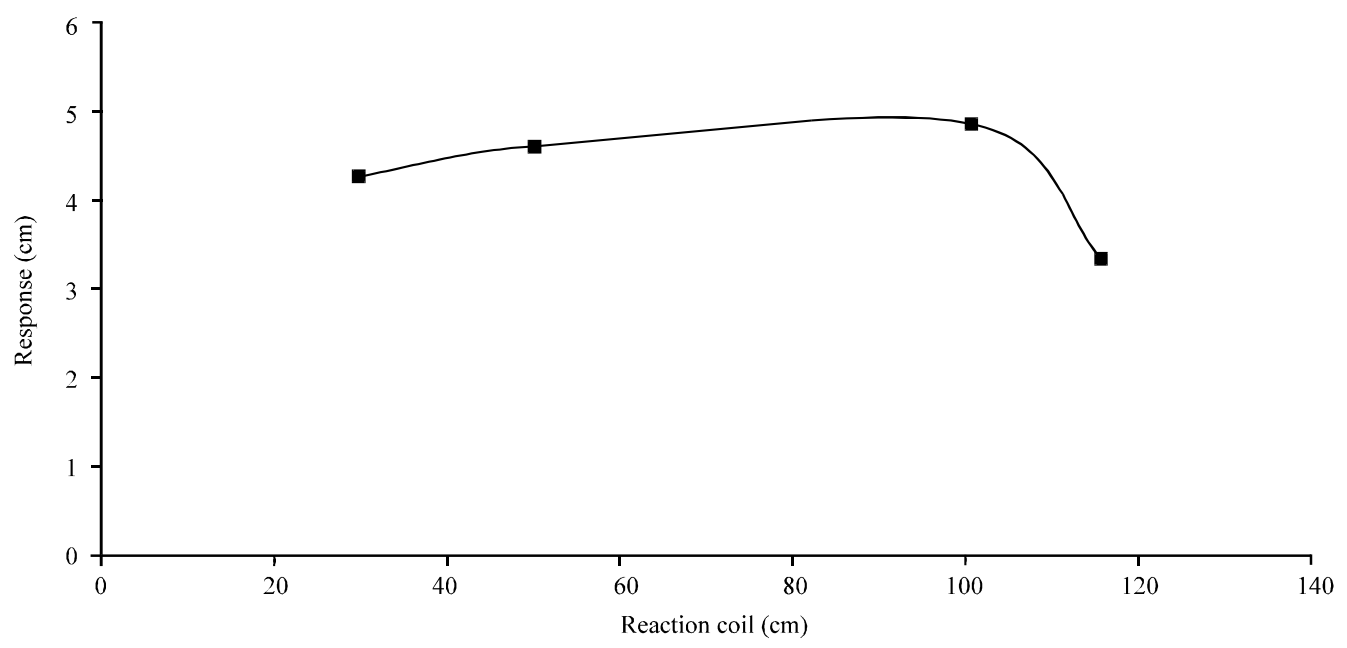

Fig. 11: Effect of reaction coil length

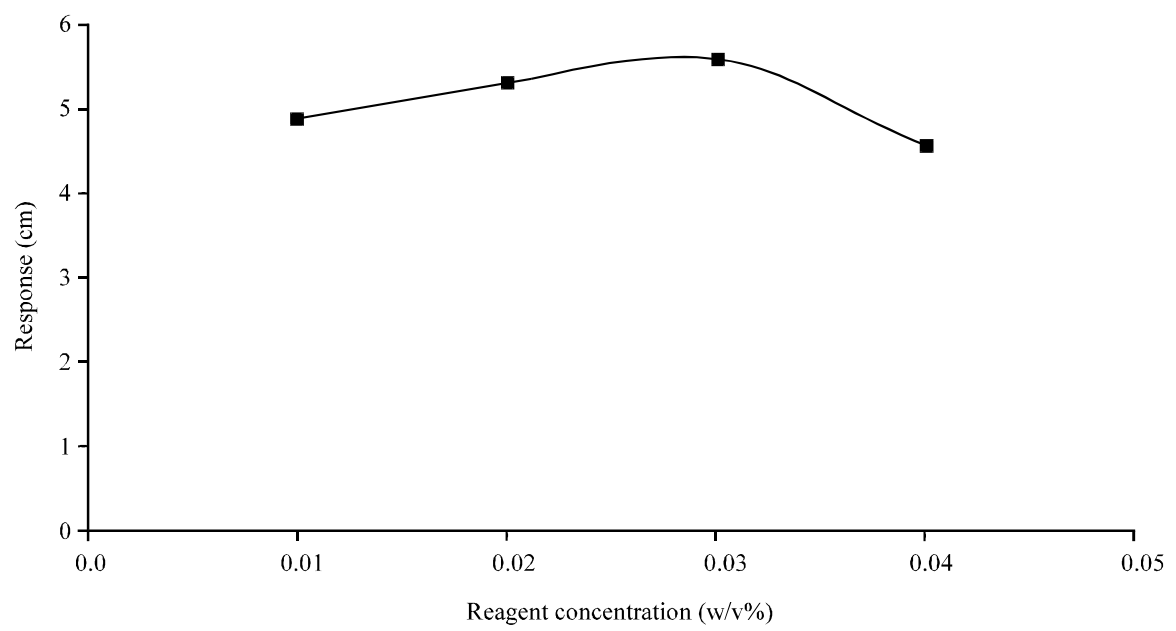

Fig. 12: Effect of reagent concentration

sample volume $(196.25 \mu \mathrm{L})$, order of addition $((\mathrm{NQS}+\mathrm{Lis})+\mathrm{B})$, sample concentration $(50 \mathrm{ppm})$ reagent concentration $(0.01 \mathrm{w} / \mathrm{v} \%)$, base concentration $(10 \mathrm{v} / \mathrm{v} \%)$.

Effect of reagent concentration: The effect of reagent concentration was studied in the range $(0.01-0.04 \mathrm{w} / \mathrm{v} \%)$ The results obtained showed that the concentration of $(0.03 \mathrm{w} / \mathrm{v} \%)$ gave the best response as shown in Table 8 and Fig. 12. This parameter was studied at: mixing time (4 min), base volume $(157 \mu \mathrm{L})$, reagent volume $(235.5 \mu \mathrm{L})$, flow rate $(8.1 \mathrm{~mL} / \mathrm{min})$ sample volume $(196.25 \mu \mathrm{L})$ order of addition $((\mathrm{NQS}+\mathrm{Lis})+\mathrm{B})$ sample concentration $(50 \mathrm{ppm})$ reaction coil $(100 \mathrm{~cm})$, base concentration $(0.03 \mathrm{w} / \mathrm{v} \%)$.

Effect of base concentration: At the following parameter, the effect of base concentration was studied in the
Table 8: Effect of reagent concentration Reagent

\begin{tabular}{lcccccc} 
concentration $(\mathrm{w} / \mathrm{v} \%)$ & ---- -Peak length $(\mathrm{cm})----$ & Means & SD & RSD $(\%)$ \\
\hline 0.01 & 4.850 & 4.900 & 4.900 & 4.883 & 0.026 & 0.532 \\
0.02 & 5.400 & 5.200 & 5.400 & 5.333 & 0.114 & 2.137 \\
0.03 & 5.600 & 5.600 & 5.600 & 5.600 & 0.000 & 0.000 \\
0.04 & 4.600 & 4.600 & 4.500 & 4.566 & 0.057 & 1.248 \\
\hline
\end{tabular}

Table 9: Effect of base concentration

Base

concentration

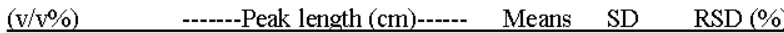

\begin{tabular}{lllllll}
\hline 6 & 2.100 & 2.250 & 2.200 & 2.183 & 0.075 & 3.435 \\
8 & 6.350 & 6.400 & 6.400 & 6.383 & 0.026 & 0.407
\end{tabular}

0.057

\begin{tabular}{lllllll}
12 & 4.850 & 4.900 & 5.000 & 4.916 & 0.075 & 1.525 \\
\hline
\end{tabular}

\begin{tabular}{lllllll}
14 & 4.200 & 4.000 & 3.900 & 4.033 & 0.152 & 3.768 \\
\hline
\end{tabular}

concentration of $(8 \mathrm{v} / \mathrm{v} \%)$ gave the greatest response as shown in Table 9 and Fig. 13. The constant parameter is: rang $(6-14 \mathrm{v} / \mathrm{v} \%)$. The results obtained showed that the 


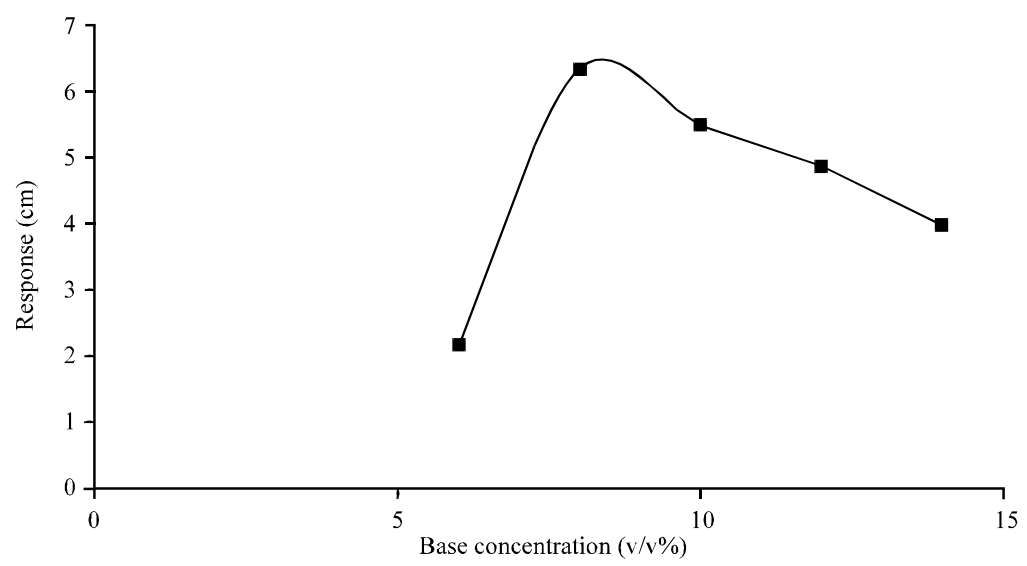

Fig. 13: Effect of base concentration

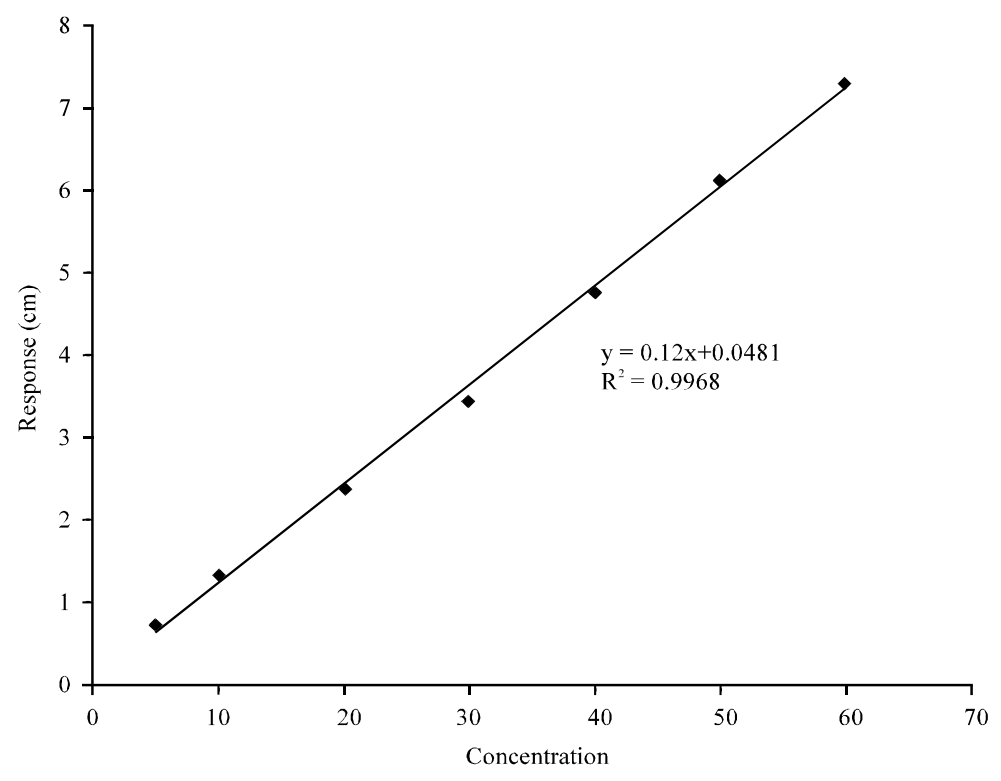

Fig. 14: Calibration graph

mixing time ( $4 \mathrm{~min})$, base volume $(157 \mu \mathrm{L})$, reagent volume $(235.5 \mu \mathrm{L})$, flow rate $(8.1 \mathrm{~mL} / \mathrm{min})$ sample volume $(196.25 \mu \mathrm{L})$, order of addition ((NQS+Lis)+B), sample concentration $(50 \mathrm{ppm})$ reaction coil $(100 \mathrm{~cm})$, reagent concentration $(0.03 \mathrm{w} / \mathrm{v} \%)$.

Calibration graph for the determination of lisinopril: Applying optimum condition mentioned above a linear calibration graph Fig. 14 and Table 10 was obtained over the concentration range of (5-60 ppm) with correlation coefficient of (0.9968) (Table 11).

Repeatability: To know the accuracy and the precision of the system, the repeatability was studied at the same perpetual parameters that it used for the constructed

\begin{tabular}{|c|c|c|c|c|c|c|}
\hline \multirow{2}{*}{$\begin{array}{l}\text { Concentration } \\
\text { (ppm) } \\
5\end{array}$} & \multicolumn{3}{|c|}{------Peak length (cm)----- } & \multirow{2}{*}{$\frac{\text { Means }}{0.733}$} & \multirow{2}{*}{$\frac{\mathrm{SD}}{0.056}$} & \multirow{2}{*}{$\frac{\operatorname{RSD}(\%)}{7.639}$} \\
\hline & 0.800 & 0.700 & 0.700 & & & \\
\hline 10 & 1.300 & 1.500 & 1.350 & 1.383 & 0.103 & 7.447 \\
\hline 20 & 2.450 & 2.450 & 2.500 & 2.466 & 0.027 & 1.094 \\
\hline 30 & 3.400 & 3.550 & 3.650 & 3.533 & 0.125 & 3.538 \\
\hline 40 & 4.800 & 4.800 & 4.850 & 4.816 & 0.027 & 0.560 \\
\hline 50 & 6.000 & 6.200 & 6.200 & 6.133 & 0.114 & 1.858 \\
\hline 60 & 7.200 & 7.400 & 7.500 & 7.366 & 0.152 & 2.063 \\
\hline
\end{tabular}

Table 11: Factors values obtained for calibration graph

\begin{tabular}{ll} 
Parameters & Values \\
\hline Linearity range $(\mathrm{ppm})$ & $5-60$ \\
Linear regression equation & $\mathrm{Y}=0.12 \mathrm{x}+0.0481$ \\
$\mathrm{R}^{2}$ & 0.9968 \\
Correlation coefficient (r) & 0.9983 \\
Relative standard deviation of $20 \mathrm{ppm}(\mathrm{n}=3)$ & 1.094 \\
Slope (m) & 0.12 \\
Intercept (i) & 0.0481 \\
\hline
\end{tabular}




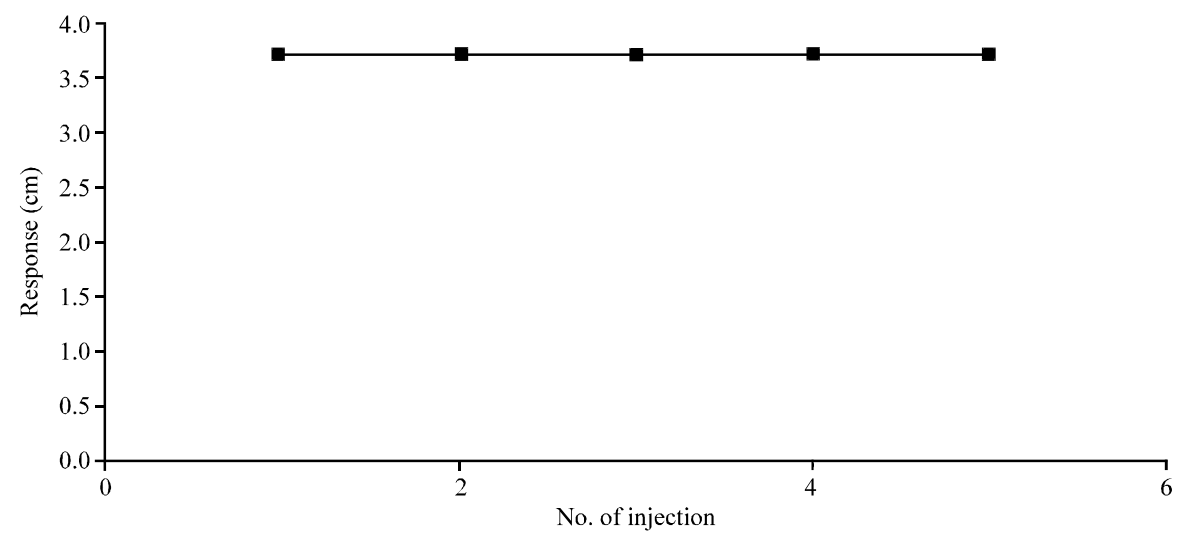

Fig. 15: Repeatability

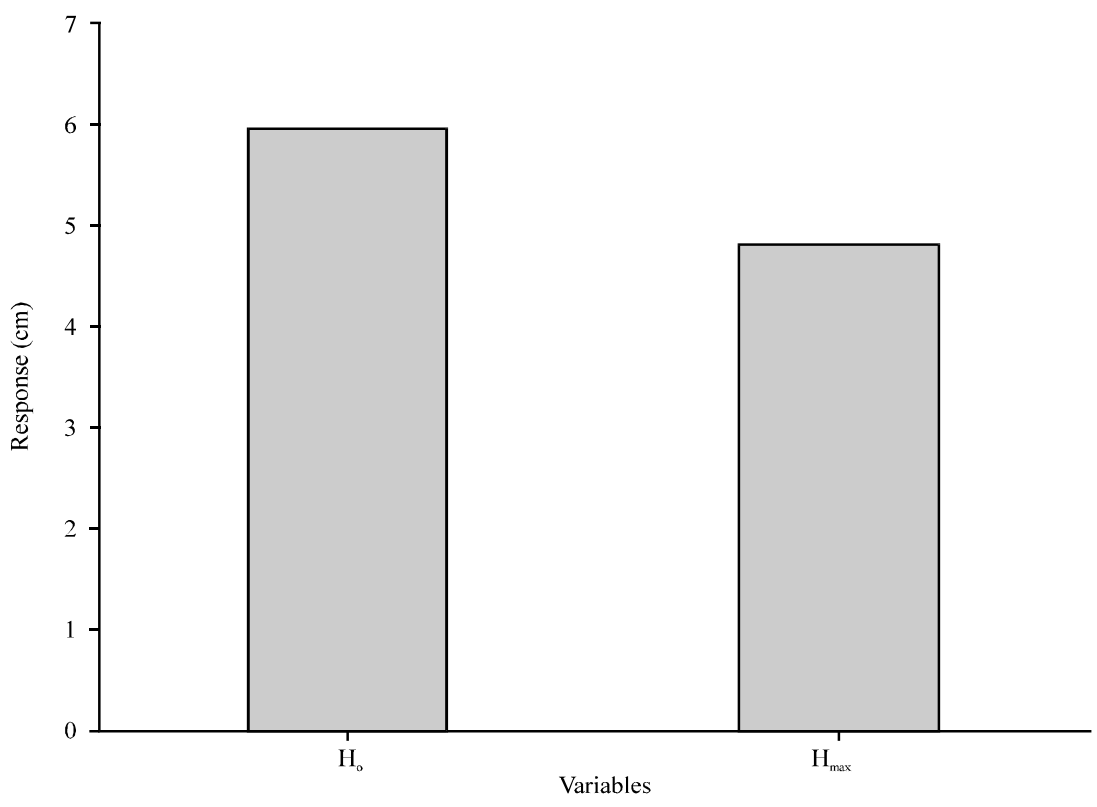

Fig. 16: The dispersion

Table 12: The repeatability

\begin{tabular}{lcllc}
\hline No. of injection & Response & Means & SD & RSD (\%) \\
\hline 1 & 3.73 & 3.736 & 0.005 & 0.133 \\
2 & 3.74 & & & \\
3 & 3.74 & & & \\
4 & 3.73 & & & \\
\hline
\end{tabular}

Table 13: The dead volume

Addition

NQS+Lis+B

Lis+NQS

$\mathrm{NQS}+\mathrm{B}$

$\underline{\mathrm{Lis}}+\mathrm{B}$

Response (cm)

1.25

0

0

calibration curve. The results Fig. 15 and Table 12 obtained exhibited that the system has a good repeatability.
The dispersion: To identify the degree of dilution of sample, the dispersion was studied at the same variable that is used of calibration curve for (40 ppm) concentration. The results attained Fig. 16 showed that the dispersion is within the desired limit.

Dead volume: To know the proficiency of the unit, the dead volume was studied Fig. 17 and Table 13 for $(10 \mathrm{ppm})$ lisinopril at the optimum parameters.

Analytical application: The analytical application of the suggested methods was investigated for pharmaceutical drugs andaqueous solution. The analytical application is shown in Table 14 and Fig. 18. 


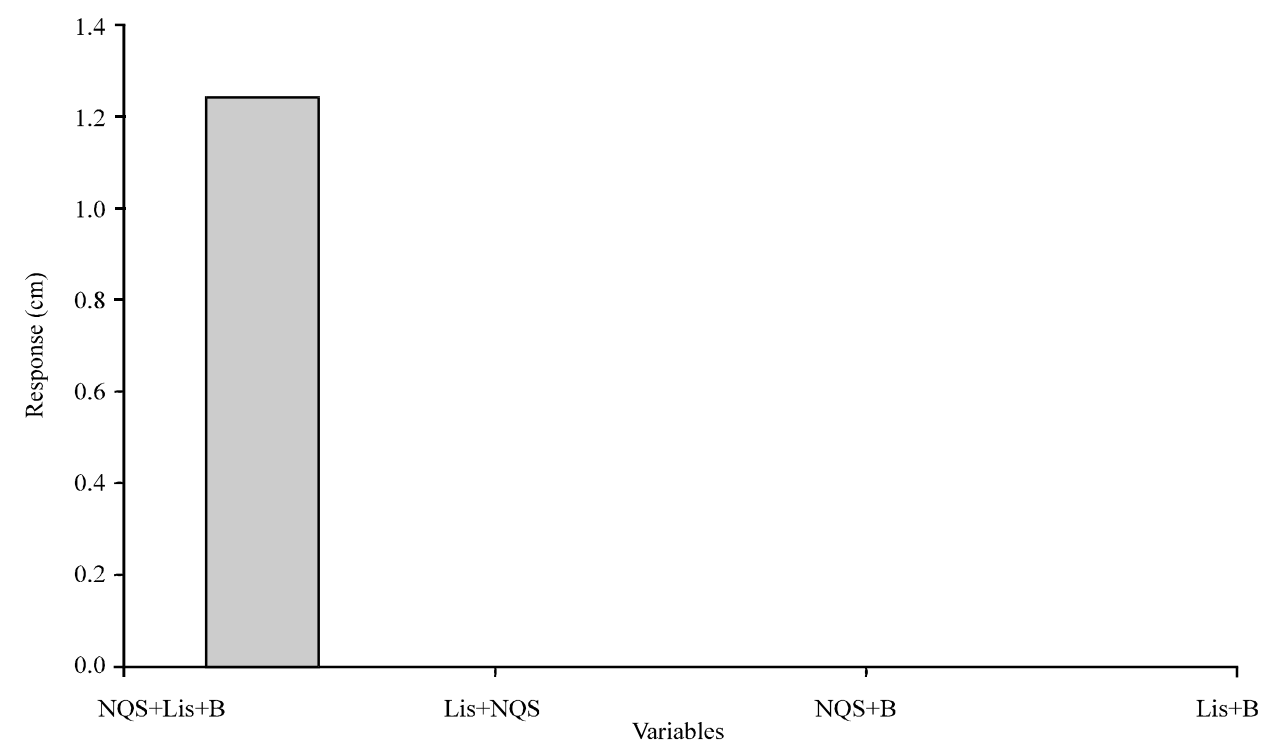

Fig. 17: The dead volume

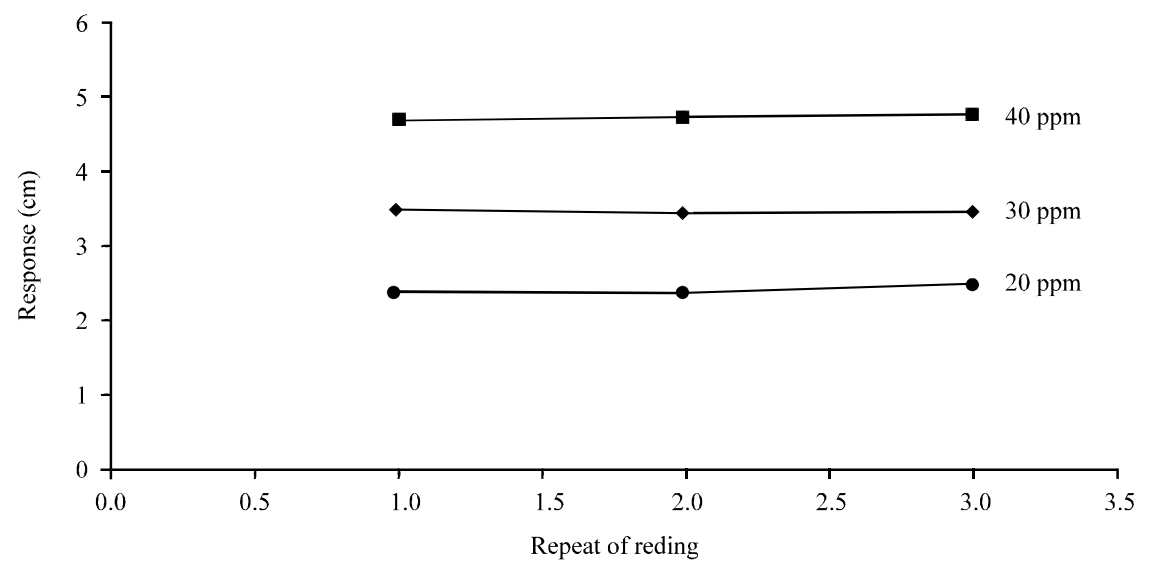

Fig. 18: Analytical application

Table 14: Analytical application

\begin{tabular}{|c|c|c|c|c|c|c|c|c|c|c|}
\hline \multirow[b]{2}{*}{$\underline{\text { Sample/reagent }}$} & \multicolumn{2}{|c|}{ Amount of sample (ppm) } & \multicolumn{8}{|c|}{ Proposed method } \\
\hline & Taken & Found & ------ & onse (cr & ---------.- & Means & SD & $\operatorname{RSD}(\%)$ & Error $(\%)$ & $\operatorname{Rec}(\%)$ \\
\hline \multicolumn{11}{|l|}{ Drugs lisinopril } \\
\hline \multirow[t]{2}{*}{ NQS } & 20 & 19.874 & 2.400 & 2. 400 & 2.500 & 2.433 & 0.057 & 2.342 & -0.630 & 99.370 \\
\hline & 30 & 28.899 & 3.550 & 3.500 & 3.500 & 3.516 & 0.028 & 0.796 & -3.670 & 96.330 \\
\hline \multicolumn{11}{|c|}{ Aqueous solution } \\
\hline NQS & 40 & 39.599 & 4.750 & 4.800 & 4.850 & 4.800 & 0.050 & 1.041 & -1.002 & 98.997 \\
\hline
\end{tabular}

\section{CONCLUSION}

Sensitive and simple FI method for the determination of lisinoprilhas been established. The developed processes based on the exchange reaction between lisinopril and NQS. This method were successfully applied inaqueous solution and pharmacy preparation.

\section{REFERENCES}

Ali, A.A.A. and A.A. Elbashi, 2013. A new spectrophotometric method for the determination of cardiovascular drugs in dosage forms. Am. Acad. Scholarly Res. J., 5: 106-121. 
American Society of Health-system, US Pharmacopeia Staff, 2008. USP Pharmacists Pharmacopeia 2008-2009. 2nd Edn., United States Pharmacopeial Convention, North Bethesda, Maryland, USA., ISBN:9781889788593, Pages: 1519.

Cakar, M. and G. Popovic, 2012. Determination of Lisinopril in pharmaceuticals by a Kinetic Spectrophotometric method. J. Serb. Chem. Soc., 77: 1437-1442.

Farhood, A.S., A.S. Majeed, L.A.M. Ali and D.N. Taha, 2017 b. Semi-automated flow injection method for the determination of Iron (II) by 1, 10-Phenanethroline. Orient. J. Chem., 33: 3112-3120.

Farhood, A.S., L.A.M. Ali and F.F. Ali, 2017a. Determination of aniline blue dye by flow injection analysis with home made valve. Orient. J. Chem., 33: 944-950.

Jamakhandi, C.M., C. Javali, J.I. Disouza, U.S. Chougule and A.K. Mullani, 2011a. Spectrophotometric determination of Lisinopril dosage form by condensation reaction. Intl. J. Pharm. Pharm. Sci., 3: 185-187.

Jamakhandi, C.M., J.I. Disouza, U.S. Chougule and M.C. Mahanthesh, 2011b. Newer spectrophotometric method of determination for Lisinopril dosage forms. Intl. J. Pharm. Pharm. Sci., 3: 255-257.

Majeed, A.S., A.S. Farhood, L.A.M. Ali and D.N. Taha, 2017. Home-made micro valve for determining malachite green dye by flow injection analysis. Indonesian J. Chem., 17: 248-255.

Meyers, F.H., E. Jawetz and A. Goldfien, 1970. Review of Medical Pharmacology. 2nd Edn., Lange Medical Publications, Los Altos, California,
Raghubabu, K. and K. Sandhyarani, 2015. Estimation of Lisinopril dihydrate in bulk and pharmaceutical preparations by visible spectrophotometry. J. Chem. Pharm. Res., 7: 636-639.

Razak, O.A., S.F. Belal, M.M. Bedair and R.S. Haggag, 2003. The utilization of Copper (II) Phosphate for the anodic stripping voltammetric assay of Alendronate Sodium, desferrioxamine mesylate and Lisinopril. Talanta, 59: 1061-1069.

Shraitah, M. and M.M.S. Okdeh, 2016. New method for spectrophotometric determination of Lisinopril in pure form and in pharmaceutical formulations. Mod. Chem. Appl., 4: 1-4.

Sultana, N., S. Naveed and M.S. Arayne, 2013. Direct determination of four ACE-inhibitors Lisinopril, Enalapril, Captopril and fosinopril in pharmaceuticals and serum by HPLC. J Chromat. Separation Techniq., 4: $1-6$.

Taha, D.N., 2002. A new approach for merging zone-flow injection analysis. Ph.D Thesis, University of Babylon, Babylon, Iraq.

Wagh, D.D., P. Dhore, D.S. Jain and D.R. Mundhada, 2012. Method development and validation of Lisinopril and Hydrochlorothiazide in comined dosage form By RP-HPLC. Intl. J. Pharm. Tech. Res., 4: $1570-1574$.

Zaheer, Z., S. Khan, M. Sadeque, M.S. Baig and J.N. Sangshetti, 2016. Development and validation of UV spectrophotometric estimation of Lisinopril dihydrate in bulk and tablet dosage form using area under curve method. J. Innovations Appl. Pharm. Sci., 1: 12-16. 